\title{
Fiber reinforcement of hydrophilic materials for a low-torque shaft seal in water environment
}

\author{
Takuro HONDA*, Yuta NAKASHIMA**, Hidehiko HIGAKI*** and Yoshitaka NAKANISHI** \\ ${ }^{*}$ Graduate School of Science and Technology, Kumamoto University \\ 2-39-1 Kurokami, Chuo-ku, Kumamoto 860-8555, Japan \\ ** Faculty of Advanced Science and Technology, Kumamoto University \\ 2-39-1 Kurokami, Chuo-ku, Kumamoto 860-8555, Japan \\ E-mail: y-naka@mech.kumamoto-u.ac.jp \\ ${ }^{* * *}$ Faculty of Life Science, Kyushu Sangyo University \\ 2-3-1 Matsukadai, Higashi-ku, Fukuoka 813-0004, Japan
}

Received: 7 November 2017; Revised: 10 December 2017; Accepted: 3 January 2018

\begin{abstract}
The lips of a shaft seal need to be lubricated to ensure its performance. Such seals are subjected to difficult conditions inside water pumps or underwater mechanical systems. Poor lubrication can cause high friction and wear of seal lips. A new shaft seal was designed to prevent water ingress with low friction and high wear resistance by adopting hydrophilic materials to seal rings. Hydrated composites for seal rings were developed with fibers to avoid excessive deformation. In experiments, cellulose nanofibers were most appropriate for reinforcement of the matrix material and the shaft seal exhibited its sealing performance at the speed of 5000 rpm under pressure of $0.8 \mathrm{MPa}$. This shaft seal will be useful not only for industrial pumps but also for generation systems driven by water flow, such as ocean current or streamflow.
\end{abstract}

Keywords : Shaft seal, Waterproof, Fiber reinforcement, Cellulose nanofiber, Polyvinyl formal

\section{Introduction}

Shaft seals are essential mechanical elements to prevent leakage from rotating shafts and are installed in various mechanical products around us. Oil seals are a typical example of a shaft seal and are often used to retain lubricating oil inside machine casing. Many studies on the sealing mechanism of such oil seals (Bock et al., 2003, Filtney, 2006) have clarified that the lubricating film formed by the pumping effect of the seal lip determines the oil seal performance. However, such a mechanism will not always be successful when an oil seal is used to prevent water leakage. This is because the seal lip of an oil seal is generally made of elastomers, which behave as hydrophobic materials. Therefore, the dynamic seal faces are likely to suffer lubricating failure in water lubricating condition. At present, alternative approaches have included applying mechanical seals and ground packings to shut out water ingress from rotating shafts like pump shafts. Today, the performance requirements of shaft seals are increasing because of advances in technology and demand for energy efficiency. For example, a new generation system has been developed that uses ocean currents as a renewable energy resource. Its turbines are submerged horizontally several tens of meters below the surface to efficiently capture the water flow (Shirasawa et al., 2016, Topaloglu et al., 2016, Honda et al., 2016, Nakanishi et al., 2016b, 2014, 2013). In such a situation, a shaft seal is needed to protect the mechanical or electrical elements from water ingress under high water pressure. In addition, the energy loss caused by the shaft seal should be minimized. To realize both a low-torque operation and high waterproofness, selecting suitable materials for the sealing material under water lubrication is important (Watt, 1973, Nakanishi, 2015b).

In previous research, a new shaft seal adopting the hydration lubrication mechanism of natural joints was developed based on the biomimetic approach (Nakanishi et al., 2016a, 2012). The shaft seal with seal rings made of hydrophilic materials performed with low frictional torque and high pressure resistance at very slow speeds (Furey and Burkhardt, 1997). Considering general specifications, such as for a pump shaft, it may be difficult for the new shaft seal to maintain the original sealing performance because of its low elasticity. To make the shaft seal robust against more 
severe operating conditions, fiber reinforcement has been suggested for the seal rings. In this study, two different reinforcement fibers were used to make hydrated composite materials for seal rings, and their performances were evaluated experimentally.

\section{Materials and methods}

A shaft seal was assembled as shown in Fig. 1. The shaft diameter was set to $8.0 \mathrm{~mm}$ to match practical applications such as for pumps or motors (Nakanishi et al 2016b). The shaft was inserted into a single seal ring, which was intended to prevent water flow. Figure 2 shows the size of the seal ring, which had a rectangular cross-section. The axial accuracy was guaranteed by the installation of a shaft seal and two bearings into the same body. The rotating shaft was made of stainless steel (SUS304, JIS) and its surface roughness was approximately $0.02 \mu \mathrm{m}$ as shown in Fig. 3 (Thomas and Werner, 2005). From a tribological viewpoint, the seal ring had a direct contact face against the rotating shaft in boundary lubrication mode. To reduce the friction caused by the seal ring and lengthen its service life, it should be made of a hydrophilic material to promote lubrication by the surrounding water (Watt, 1973).

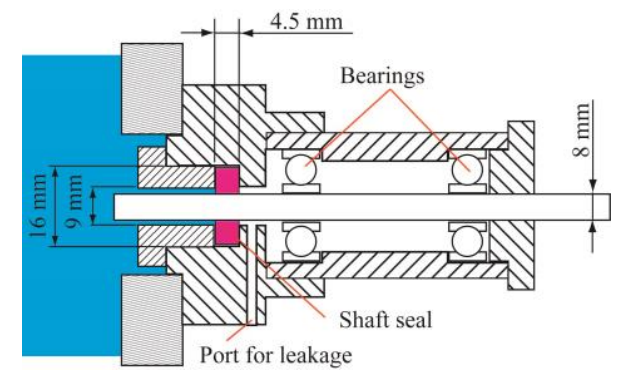

Fig. 1 Schematic illustration of the shaft seal holder and seal ring

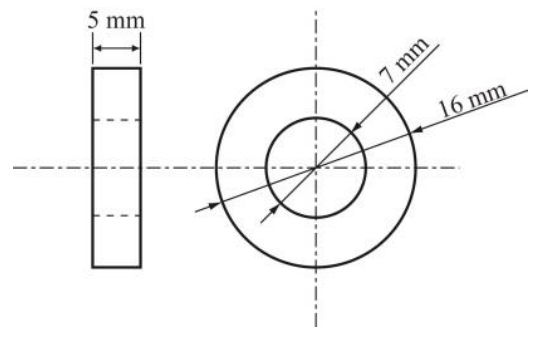

Fig. 2 Shape of the hydrated seal ring installed in the shaft seal holder

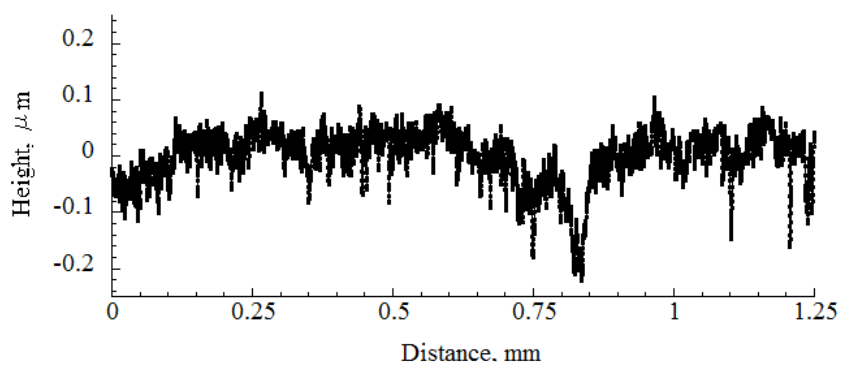

Fig. 3 Surface roughness of a rotating shaft for seal performance test

Polyvinyl formal (PVF) is made from polyvinyl alcohol (PVA) and was developed as a hydrophilic sealing material (Nakanishi, 2009, Chang et al., 2017). Figure 4 shows the method for synthesizing PVF. PVA was added as a hydrophilic base to distilled water and agitated for $48 \mathrm{~h}$ at $50{ }^{\circ} \mathrm{C}$. The PVA solution was crosslinked and cured by formalization in the presence of $100 \mathrm{wt} \% \mathrm{H}_{2} \mathrm{SO}_{4}$ as an acid catalyst and $50 \mathrm{wt} \% \mathrm{HCHO}$ as a crosslinker based on PVA. After molding for $18 \mathrm{~h}$ at $25^{\circ} \mathrm{C}$, the reaction product was neutralized by $\mathrm{NaOH}$ and washed with fresh water. The pure PVF (Fig. 4(a)) showed low frictional characteristics and wear resistance. Because PVF has a low elastic modulus, there is concern over large deformation leading to leakage path generation caused by external forces such as water pressure or the frictional force in the circumferential direction. Fiber reinforcement was introduced as a solution to the problem of using PVF (Manjula et al., 2017, Abdul et al., 2012, Bamdad et al., 2016). Hydrated fibers are considered to provide advantages in bonding with the matrix material of PVF. Among the chemical fibers available, polyester fibers with hydrophilic functional groups were chosen and prepared in the form of nonwoven fabrics (Kuraray Co. Ltd., Japan). The diameter of polyester fibers was $3 \mu \mathrm{m}$, and the length of them was longer than $1 \mathrm{~mm}$ (Fig. 5 (a)).The reaction solution of PVF was impregnated into the polyester fiber sheet (Fig. 4(b)). Although at a disadvantage in terms of procurement and refining compared to chemical fibers, cellulose fibers were also adopted for reinforcement. These are representative of natural fibers, which are more hydrophilic. In the field of fiber reinforcement, "green composites" have been developed from natural fibers and are available for practical use (Abdul et al., 2012, Bamdad et al., 2016). Based on the dispersibility of the fibers in the matrix material, cellulose nanofibers (ARBOCEL MF40-40, J. RETTENMAIER \& SÖHNE GmbH Co. KG, Germany) were used for this experiment and mixed with the PVA 
solution beforehand (Fig. 4(c)). Cellulose fibers (Fig. 5(b)) showed much lower aspect ratio than polyester fibers (Fig. $5(\mathrm{a})$ ), therefore, it is difficult to detect the diameter or the length in scanning electron microscope (SEM) observations (TM3030, Hitachi High-Technologies Co. Ltd., Japan). Each reinforcement fibers were mixed at 10 wt\% of PVA.

These sealing materials were molded into a flat sheet to the desired thickness and cut with a Thomson die. Table 1 summarizes the sealing materials used for the test. An oil seal generally used in machines (AC0158A8, NOK Co. Ltd., Japan) was also tested for comparison.

Figure 6 shows the seal performance testing device. The shaft seal assembly in Fig. 1 was attached to the water chamber. The shaft was rotated at a constant speed of $5000 \mathrm{rpm}$ by an AC servomotor (NX-45, Oriental Motor Co. Ltd., Japan). The frictional torque caused by the shaft seal was calculated according to the relationship between the rated torque of the motor and the power consumption. The water pressure applied to the shaft seal was adjusted by the compressed air in the chamber and increased by $0.1 \mathrm{MPa} / \mathrm{h}$ to a maximum of $0.8 \mathrm{MPa}$, as shown in Fig. 7 . The mean value of the frictional torque was calculated, and the amount of leakage was measured under each pressure condition. Table 2 summarizes the experimental conditions. The sealing surfaces were observed before and after the test with a SEM. Figure 8 shows pictures of each shaft seal surface obtained before the test. Tensile tests were also conducted to measure the elasticity of prepared seal materials by using a material tester (EZ-LX, Shimadzu Co., Japan).

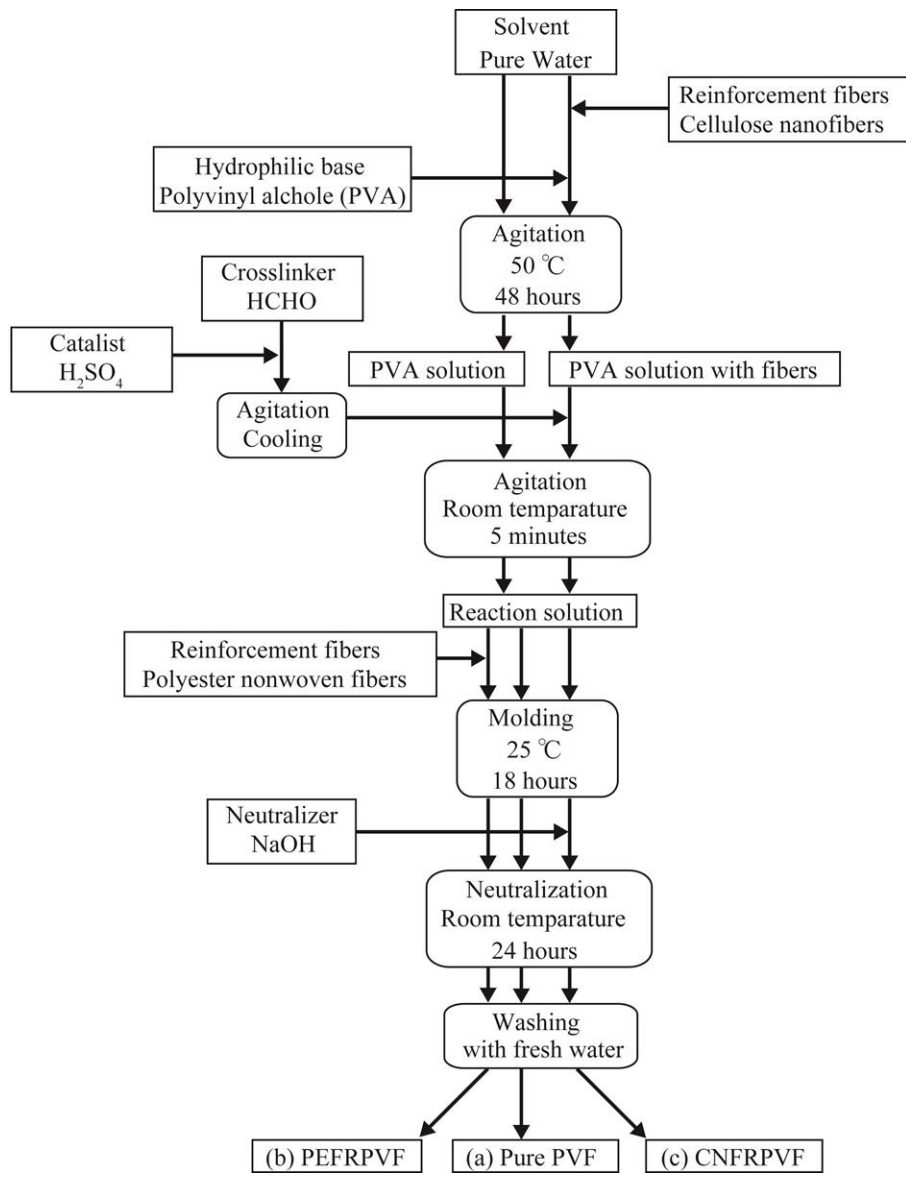

Fig. 4 Preparation process for a hydrated seal ring:

(a) pure PVF seal ring, (b) polyester fiber-reinforced PVF seal ring, and (c) cellulose fiber-reinforced PVF seal ring
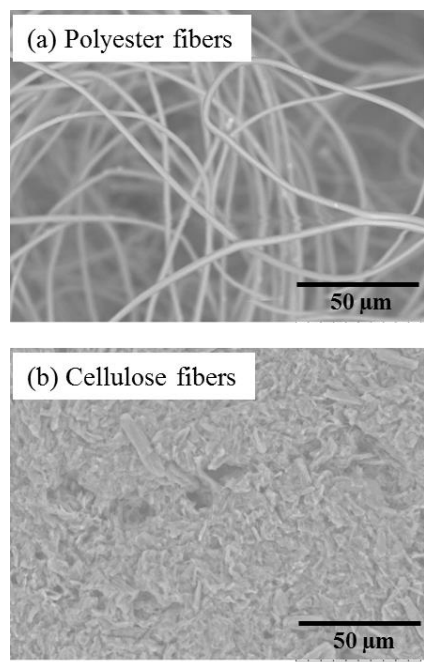

Fig. 5 SEM images of reinforcement fibers: (a) polyester fibers, (b) cellulose fibers

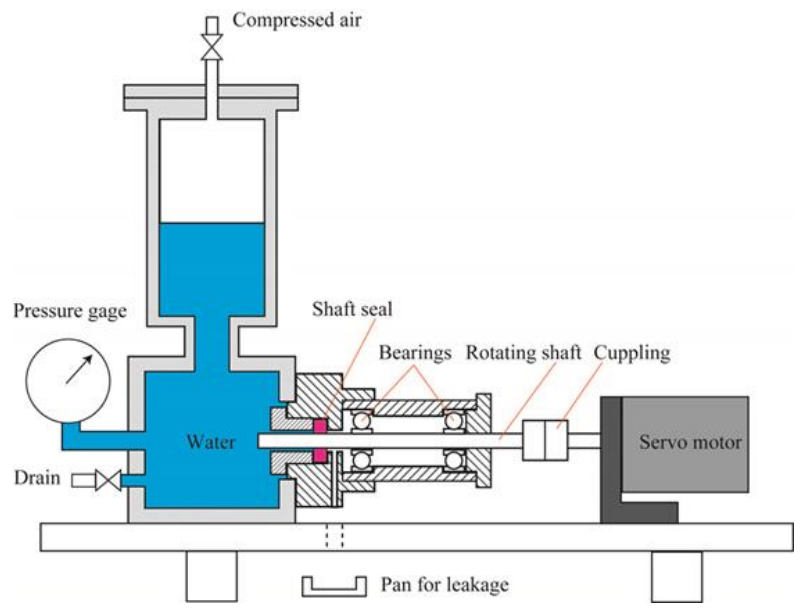

Fig. 6 Schematic illustration of the seal performance testing device 
Table 1 Shaft seals prepared for the seal performance test

\begin{tabular}{cccc}
\hline \multicolumn{3}{c}{ Shaft seals used for the test } \\
\hline Oil seal & Pure PVF & Polyester fiber-reinforced PVF & Cellulose fiber-reinforced PVF \\
\hline
\end{tabular}

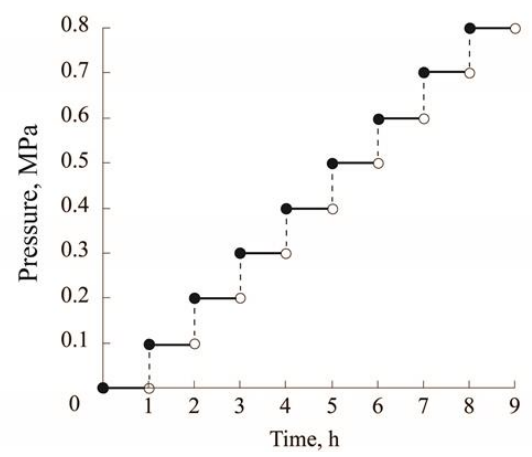

Table 2 Seal performance test conditions

\begin{tabular}{cc}
\hline Parameters & Values \\
\hline Shaft diameter, mm & 8.0 \\
Shaft speed, rpm & 5000 \\
Water pressure, $\mathrm{MPa}$ & $0.1-0.8$ (Fig. 5) \\
Temperature, ${ }^{\circ} \mathrm{C}$ & 20 \\
\hline
\end{tabular}

Fig. 7 Pressure conditions during the test

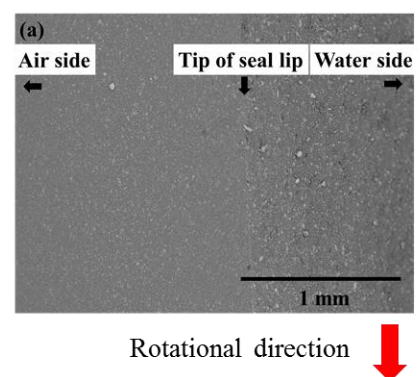

Rotational direction
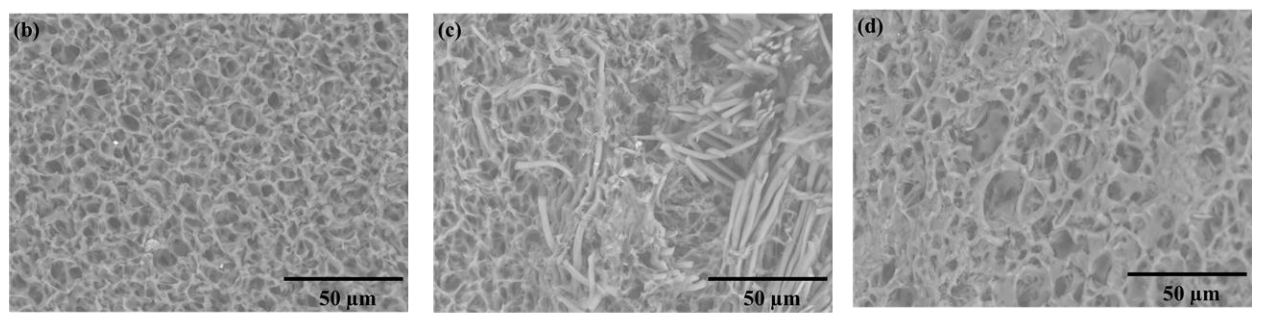

Fig. 8 SEM images of each shaft seal before the test: (a) oil seal, (b) pure PVF, (c) polyester fiber-reinforced PVF, and (d) cellulose fiber-reinforced PVF.

\section{Results}

Figure 9 shows the relationship between the water pressure and the frictional torque caused by each shaft seal and the total leakage. In the case of the oil seal (Fig. 9 (a)), the frictional torque measured was high under a pressure of 0 to $0.2 \mathrm{MPa}$, and it decreased gradually as the applied pressure and elapsed time increased. When the pressure reached 0.6 $\mathrm{MPa}$, the frictional torque increased drastically. There was little leakage during the experiment, but a scratching noise and wear debris of the elastomer were detected. The pure PVF seal showed the tendencies observed for the oil seal but a slightly lower mean value for the torque (Fig. 9(b)). Although there was no PVF debris, the seal ring was deformed by the water pressure and sometimes pushed out from the seal holder. The polyester fiber-reinforced PVF (PEFRPVF) seal recorded the highest frictional torque in the first period (Fig. 9(c)). The torque decreased after pressurization and was lower than that for the oil seal while being less sensitive to the pressure. However, leakage from the PEFRPVF seal was detected throughout the test. On the other hand, the cellulose nanofiber-reinforced PVF (CNFRPVF) seal exhibited low frictional torque operation from the start of the experiment, and increasing the pressure had almost no influence on the frictional torque (Fig. 9(d)). The amount of leakage from the CNFRPVF seal was under $0.1 \mathrm{~mL} / \mathrm{h}$, which is sufficient for practical application.

Figure 10 compares the pictures of each shaft seal before and after the test. The seal lip of the oil seal was heavily damaged after the test. There was small deformation due to water pressure in the PVF seals, including those with reinforcement fibers, but macroscopic observation detected no wear of the seal rings.

The SEM was used to evaluate the sliding surface of each shaft seal microscopically, as shown in Figs. 11. Damage was observed in the oil seal from the tip of the seal lip to the air side, and the sliding surface was rough due to chipping and cracks (Fig. 11(a)). In the case of the pure PVF seal, the characteristic porous structure of PVF was squeezed rather than wear phenomena manifesting. In particular, the squeezed parts were observed on the air side surface rather than on the water side surface (Fig. 11 (b)). The PVF pores in the PEFRPVF seal were also squeezed, and the reinforcing polyester fibers were oriented toward the rotational direction, as shown in Fig. 11 (c). Unlike the other seals, the CNFRPVF seal maintained its porous structure even after the test (Fig. 11 (d)). 
Figure 12 shows the stain-stress curves of seal materials: (a) pure PVF and (b)PEFRPVF, (c)CNFRPVF. The average elastic modulus of pure PVF was $1.1 \times 10^{-3} \mathrm{MPa}$. That of PEFRPVF was increased to $0.49 \mathrm{MPa}$, but the that of CNFRPVF was almost equivalent level $\left(1.0 \times 10^{-3} \mathrm{MPa}\right)$.

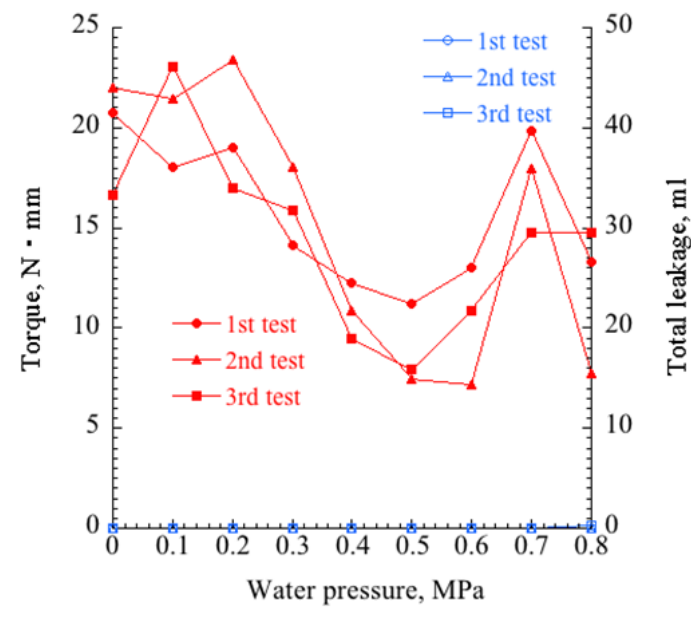

(a) Oil seal

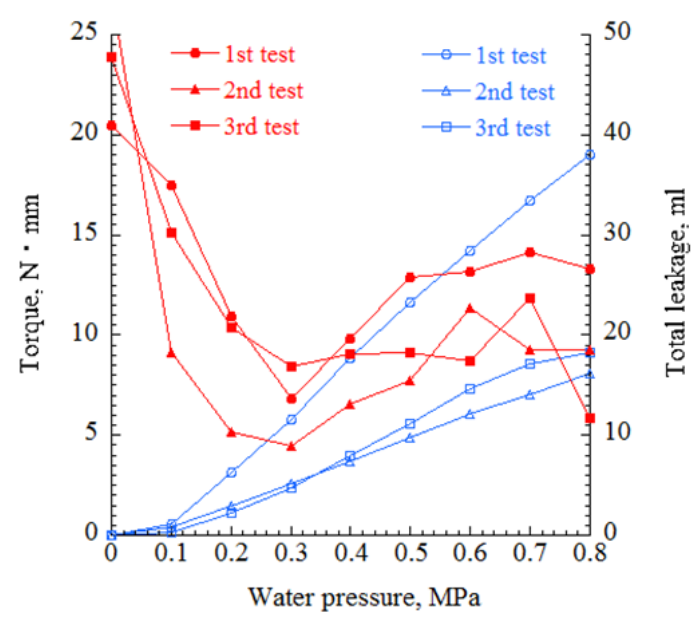

(c) Polyester fiber-reinforced PVF

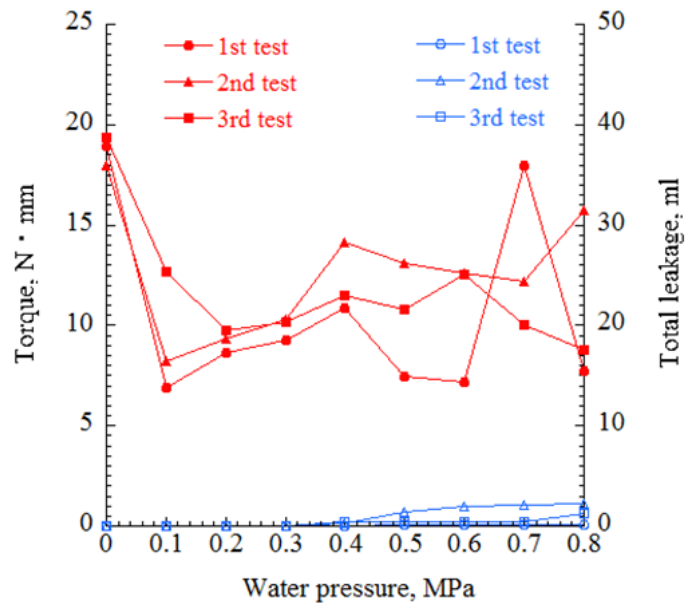

(b) Pure PVF

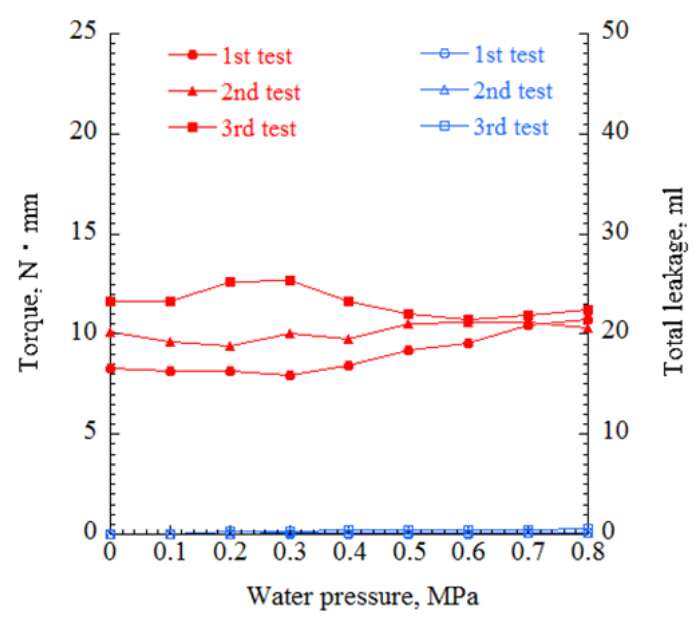

(d) Cellulose fiber-reinforced PVF

Fig. 9 Relationships between the water pressure applied to the shaft seals and the frictional torque or amount of leakage caused by each shaft seal: (a) oil seal, (b) pure PVF, (c) polyester fiber-reinforced PVF, and (d) cellulose fiber-reinforced PVF.

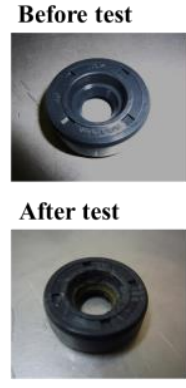

(a)
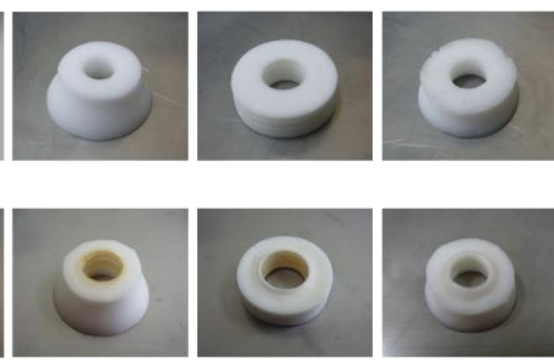

(b)

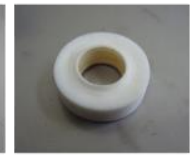

(c)

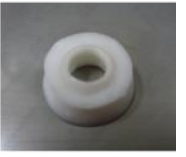

(d)

Fig. 10 Comparison of each shaft seal before and after the test: (a) oil seal, (b) pure PVF, (c) polyester fiber-reinforced PVF, and (d) cellulose fiber-reinforced PVF 


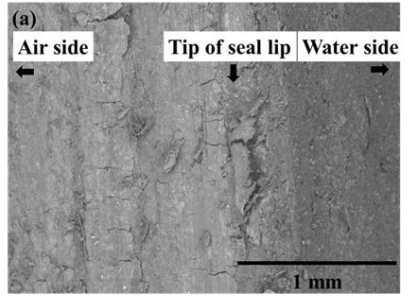

Rotational direction
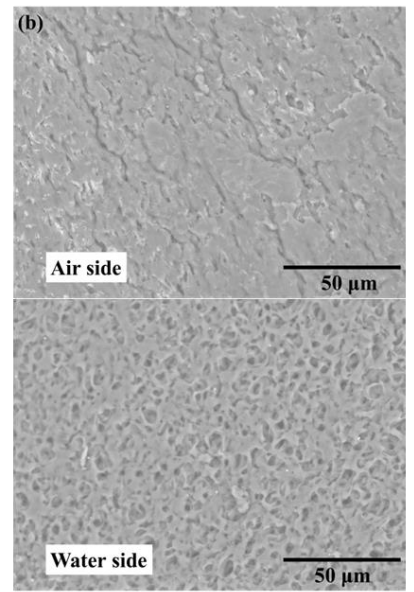
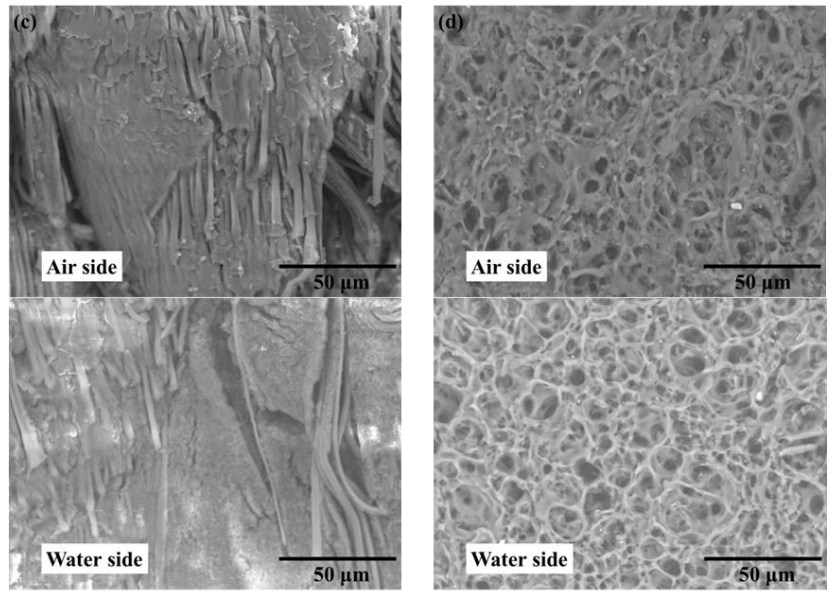

Fig. 11 SEM images of each shaft seal after the test: (a) oil seal, (b) pure PVF, (c) polyester fiber-reinforced PVF, and (d) cellulose fiber-reinforced PVF.

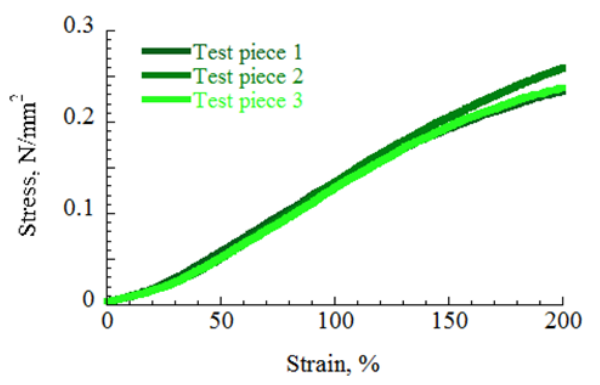

(a) Pure PVF

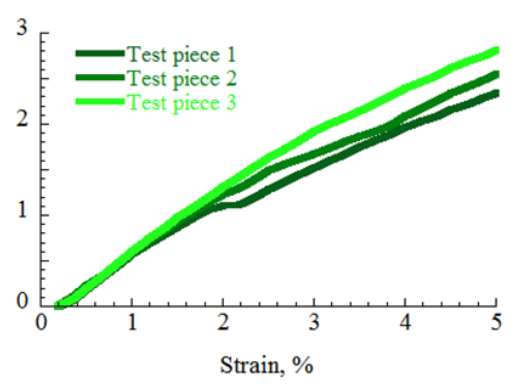

(b) Polyester fiber-reinforced PVF

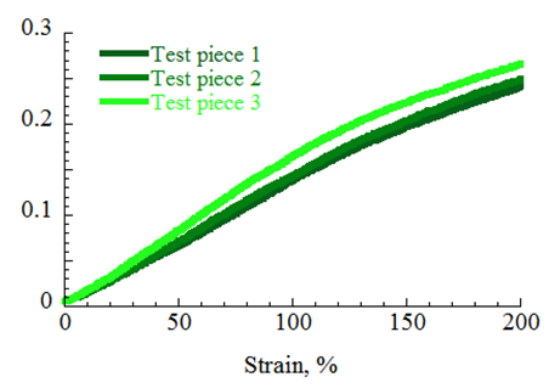

(c) Cellulose fiber-reinforced PVF

Fig. 12 Strain-Stress curves of each seal material: (a) pure PVF, (b) polyester fiber-reinforced PVF, and (c) cellulose fiber-reinforced PVF

\section{Disucussion}

The shaft seal using a hydrated material for the seal ring realized both low torque operation and reliable waterproofness in a water environment. To shield the subject from fluids, a reasonable approach is to tighten the connection between the shaft and seal ring. However, this increases the frictional loss and results in a short service life for the shaft seal because of wear. Promoting lubrication at the sliding surface of the shaft seal is important to realize low friction and high durability.

Oil seals show a great sealing performance under the oil lubricating condition because the seal lip is made of elastomer, which has hydrophobic characteristics. However, it was thought that they would not work well under the current test conditions using water as a subject fluid because their hydrophobic seal lips would prevent lubrication (Stefan et al., 2017). The high frictional torque recorded at the start of the test was caused by this material problem (Fig. 9(a)). When the water pressure increased, the torque decreased because water was pushed into the sliding surface.

Normal operation

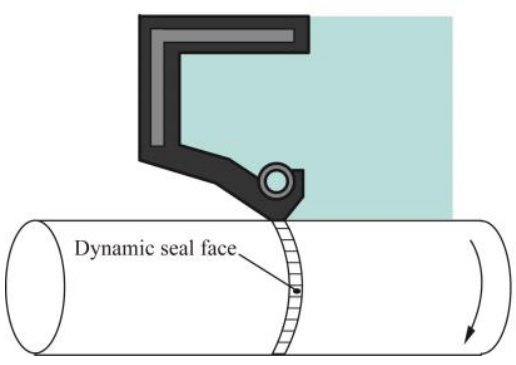

Fig. 13 Consideration of the seal lip figure in different operation modes: oil seal 
After the pressure exceeded the threshold, the torque increased again because of the increased contact surface. The seal lip of an oil seal is designed to have a pumping effect to form a fluid lubrication film derived from an asymmetric shape (Bock et al., 2003, Filtney, 2006). When an excessive pressure load is applied to the seal lip, the seal lip deforms as shown in Fig. 13, and the area of the contact surface increases. This mechanism explains the high friction and excessive wear of the oil seal. SEM observation supported this theory (Fig. 11(a)).

On the other hand, the hydration lubrication of the pure PVF seal was successful at the molecular level, even when its seal ring was in boundary lubrication mode, because PVF is a hydrophilic material (Briscoe, 2017). Although the pure PVF seal showed lower friction and wear than the oil seal made of a hydrophobic material, PVF itself is a very soft material and easy to deform with increased pressure. As shown in Fig. 14, the seal ring experienced a large deformation, which caused a sudden increase in frictional torque.

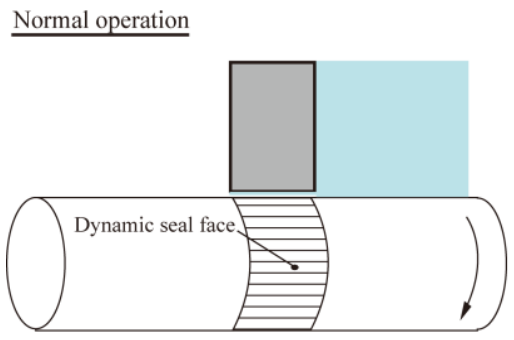

Under high pressure condition (without reinforcement fibers)

Fig. 14 Consideration of the seal lip figure in different operation modes: PVF seal

To compensate for this disadvantage, fiber reinforcement of PVF has been suggested (Manjula et al., 2017, Abdul et al., 2012, Bamdad et al., 2016). The results showed that polyester fibers were not very effective as reinforcement for PVF. During the seal lip cutting process, the reinforcement fibers were exposed on the sliding surface. Therefore, their direct contact with the shaft surface caused the torque to increase early in the test. In addition, voids at the boundary between fibers and PVF or the non-uniform distribution of the fibers led to the creation of leakage paths. As another reinforcement material, cellulose nanofibers were found to effectively enhance the sealing performance. Nanoscale fibers contributed to the creation of a homogenous material because the fibers could be dispersed in the matrix material compared to laminated fibers. In addition, cellulose fibers are polar materials derived from hydrophilic groups as well as water and PVA, which has advantages in dispersibility in water and interface adhesion between PVA (Bamdad et al., 2016, Tian et al., 2017). These characteristics are important to produce high-quality composite materials although the increase in elasticity of CNFRPVF wasn't confirmed by tensile tests. Even if the exposed fibers touched the shaft surface, hydration lubrication should occur because of the hydrophilicity of cellulose fibers. As a result, the CNFRPVF seal recorded the lowest frictional torque with little leakage and was not influenced by the applied pressure.

\section{Conclusion}

A shaft seal for separating water and air was successfully designed by the adoption of hydrophilic materials for its seal ring. It provides waterproofness with low friction to reduce energy loss and wear. It was thought that the hydrophilicity of seal lips helped hydrated lubrication between a shaft and a seal lip, and it led to reduction in frictional torque caused by shaft seals. Fiber reinforcement of PVF seals allowed to perform a sealing function under a pressure of $0.8 \mathrm{MPa}$ without increase in frictional torque. It was suggested that seal lips was able to keep proper contact state because a deformation of the seal lip due to water pressure was suppressed by reinforcement fibers. Cellulose nanofibers were found to be effective candidates at creating a hydrated composite material for seal lips. As a future work, the size of cellulose fibers or mix ratio in the composite should be optimized and the mechanical strength of the composite should be investigated.

\section{Acknowledgments}

This work was supported by the Kyushu Natural Energy Promotion Organization and New Energy and Industrial Technology Development Organization (NEDO) [11B04011c]. 


\section{References}

Abdul Khalil HPS, Bhat AH, Ireana Yusra AF. Green composites from sustainable cellulose nanofibrils. Carbohydr Polym, Vol.87, (2012), pp.963-979.

Bamdad B, Emad O, Afsaneh DM, Pradeep LM, Krishna MP, Pradeep KR. Mechanical, physical and tribological characterization of nano-cellulose fibers reinforced bio-epoxy composites: An attempt to fabricate and scale the "Green" composite. Carbohydr Polym, Vol.147, (2016), pp.282-293.

Bock E, Vogt R, Schreiner P. New radial shaft seal concept for sealing hydraulic pumps and motors. Seal Technol, Vol.11, (2003), pp.6-10.

Briscoe WH. Aqueous boundary lubrication: Molecular mechanisms, design strategy, and terra incognita, Curr Opin Colloid Interface Sci Vol.27, (2017), pp.1-8.

Chang Y-I, Yang Y-Y, Cheng W-Y, Jang L. Making PVF porous sponge with and without using the pore-forming agent. J. Taiwan Inst Chem Eng, Vol.74, (2017), pp.246-254.

Flitney B. Advances in understanding of polymer seals for rotating applications. Seal Technol, Vol.11, (2010), pp.7-11.

Furey MJ, Burkhardt MJ. Biotribology: Friction, wear, and lubrication of natural synovial joints. Lubr Sci, Vol.9, (1997), pp.255-271.

Honda T, Nakanishi Y, Kasamura K, Nakashima Y, Higaki H. An ideal generation system for streamflow, tidal and ocean currents: Installation of biomimetic sealing system. Renew Energy Res Appl, (2016), pp.596-599, DOI: 10.1109/ICRERA.2015.7418483.

Manjula P, Govindan S, Vidya SK. Biocomposite composed of PVA reinforced with cellulose microfibers isolated from biofuel industrial dissipate: Jatropha Curcus L. seed shell. J. Environ Chem Eng, Vol.5, (2017), pp.1990-1997.

Nakanishi Y, Honda T, Nakashima Y, Higaki H. Shaft seal for separation of water and air with low frictional torque. Tribol Int, Vol.94, (2016a), pp.437-445.

Nakanishi Y, Honda T, Kasamura K, Nakashima Y, Nakano K, Kondo K, Higaki H. Bio-inspired shaft seal in coolant pump for electric vehicles, Renew Energy Res Appl, (2016b) DOI: 10.1109/ICRERA.2016.7884449

Nakanishi Y, Sanderson J, Honda T, Kasamura K, Nakashima Y, Higaki H. Influence of axial direction on performance of biomimetic sealing system. Renew Energy Res Appl, (2015a), pp. 263-266, DOI: 10.1109/ICRERA.2015.7418706.

Nakanishi Y. Hydrated materials: Applications in biomedicine and environment. Singapore: Pan Stanford, (2015b), ISBN: 9789814463225.

Nakanishi Y, Oka Y, Sanderson J, Honda T, Kasamura K, Nakashima Y, Higaki H. Biomimetic sealing system with hydrated materials for ocean current or tidal power generation. Renew Energy Res Appl, (2014), pp.755-759, DOI: 10.1109/ICRERA.2014.7016486.

Nakanishi Y, Shimazu K, Oka Y, Mine S, Matsumoto Y, Kai S, Higaki H. Biomimetic sealing system for streamflow generation. Renew Energy Res Appl, (2013), pp.211-214, DOI: 10.1109/ICRERA.2013.6749753.

Nakanishi Y, Shimazu K, Matsumoto Y, Kai S, Higaki H, Oka Y. Eco-friendly bearing for tidal power generation. Renew Energy Res Appl, (2012), pp.1-5, DOI: 10.1109/ICRERA.2012.6477470.

Nakanishi Y, Takashima T, Higaki H, Shimoto K, Umeno T, Miura H, Iwamoto Y. Development of biomimetic bearing with hydrated materials. J Biomech Sci Eng, Vol.4, (2009), pp.249-264.

Shirasawa K, Tokunaga K, Iwashita H, Shintake T. Experimental verification of a floating ocean-current turbine with a single rotor for use in Kuroshio currents. Renew Energy, Vol.91, (2016), pp.189-195.

Stefan T, Marian M, Otto VE. On the stick-slip behavior of water-lubricated rubber sealings, J Sound Vib, Vol.399,(2017), pp.151-168.

Thomas K, Werner H. Shaft surface manufacturing methods for rotary shaft lip seals. Seal Technol, Vol.7(2005), pp.59.

Tian Y, Zhang H, Zhang Z, Influence of nanoparticle on the interfacial properties of fiber-reinforced-epoxy composite, Comp.Part A,(2017),pp.1-8

Topaloglu I, Nakanishi Y, Korkmaz F, Nakashima Y. Flux permanent magnet generator with low cogging torque for maintenance free underwater power generating system. Int J Renew Energy Res, Vol.2, (2016), pp.511-519.

Watt SV. Material selection criteria for water lubrication. Wear, Vol.25, (1973), pp.139-153. 